\title{
Why habitat architecture and color are important to shrimps living in pelagic Sargassum: use of camouflage and plant-part mimicry
}

\author{
Sally D. Hacker, Laurence P. Madin \\ Biology Department, Woods Hole Oceanographic Institution, Woods Hole, Massachusetts 02543, USA
}

\begin{abstract}
Camouflage and plant-part mimicry, 2 forms of resemblance of animals to their habitat, were investigated for 2 species of shrimps living in pelagic Sargassum natans (Linnaeus) Gaillon in the Sargasso Sea. We used field collections and laboratory experiments to correlate the size, shape, color, and behavior of Latreutes fucorum (Fabricius) and Hippolyte coerulescens (Fabricius) with the architecture and color of the Sargassum habitat (i.e. the number, size, shape and arrangement of structural components of the habitat). Components of the structural architecture of Sargassum and plastic plants were measured and related to shrimp number, body size and shape. Latreutes most resembled Sargassum fronds, while Hippolyte resembled the gas-filled bladders (vesicles). Behavioral observations showed that Latreutes characteristically clings to the fronds and Hippolyte to the main stalk and vesicles of Sargassum plants. In habitat selection experiments, the shrimps were offered Sargassum and artificial algae with different architectures and colors. Both species were found in equal densities on Sargassum and artificial algae suggesting that food value was unimportant relative to habitat architecture. When offered a modified habitat architecture of Sargassum, Latreutes preferred a 'fronds only' to a 'vesicles only' plant while the reverse was true for Hippolyte. When plastic plants with small and large fronds were offered, small Latreutes showed a significant preference for small-frond plants, while large shrimp showed no preference. This was also true in the presence of a predator. Latreutes chose yellow artificial plants significantly more than brown artificial plants but Hippolyte chose both plants equally. In general, small shrimps of both species tend to be solid-colored or transparent, while large shrimps have disruptive color patterns corresponding to their habitat. It may be that there is an ontogenetic shift from use of plant-part mimicry to camouflage. As shrimps outgrow the specific plant parts they mimic, they use color patterns to camouflage themselves and generally resemble the Sargassum habitat matrix. In this system, camouflage and plant-part mimicry may depend, in large part, on the size, shape and color of the shrimps relative to elements of the Sargassum habitat, and may change in importance as the shrimps grow larger. The importance of fish predation is discussed in relation to the shrimps and fishes found in Sargassum collections from this study.
\end{abstract}

\section{INTRODUCTION}

An important component of habitat use by terrestrial, freshwater, and marine arthropods is protection from predation afforded them by their habitat (e.g. Huffaker 1958, Heck \& Wetstone 1977, Coull \& Wells 1983, Leber 1985, Feltmate et al. 1986, Main 1987, Wellborn \& Robinson 1987, Holomuzki \& Short 1988, Eggleston et al. 1990, Hay et al. 1990, Holmlund et al. 1990, Kareiva \& Sahakian 1990). There are numerous examples of arthropods that resemble their habitat and gain protection from predators (see Wickler 1968 and Wicksten 1983 for reviews). Terrestrial examples such as the stick and leaf insects (Robinson 1969, Bedford 1978,
Carlberg 1986) and the peppered moth (Kettlewell 1956) are well known. In the marine literature, there are equally fascinating examples, such as the tidepool decorator crab (Wicksten 1980) and caprellid amphipods (Keith 1971). However, relatively few marine studies (see Bauer 1981, Nilsson \& Nilsson 1983, Bowman \& Wasmer 1984, Patton et al. 1985) have looked at the use of habitat resemblance by smaller marine crustaceans that may be the functional equivalents of insects in terrestrial systems because they are small in size (compared to their habitat), highly mobile, susceptible to heavy predation, and rarely experience competition for food (Hay et al. 1987, 1990, Hacker \& Steneck 1990). 
The shrimp community living in pelagic Sargassum is a good example of small crustaceans that are noted for their well-developed resemblance to Sargassum (Gurney 1936, Brown 1939, Sisson 1976, Williams 1984) but are virtually unstudied in terms of the processes and mechanisms that facilitate this resemblance. In this study, 2 species of shrimps that reside in pelagic Sargassum natans (Linnaeus) Gaillon (hereafter referred to by genus) in the Sargasso Sea, and are preyed on by fish living in Sargassum (Adams 1960, Dooley 1972, Smith 1973), were measured and experimentally manipulated to determine whether a relationship exists between the body size and color of shrimps and the architecture and color of their habitat. Habitat architecture (sensu Hacker \& Steneck 1990) is the number, size, shape, and arrangement of spatial and structural components of the habitat. In general, the structural architecture of the pelagic Sargassum habitat is characterized by having elongated, narrow fronds with spiny edges and numerous spherical gas-filled bladders called vesicles (with spur-like projections protruding out from one end) which allow the plant to float freely (Littler et al. 1989). The color of Sargassum can vary from yellow to brown to black.

The terminology associated with the concept of hiding by resembling a habitat has become confused by the many variations on the theme of resemblance (Vane-Wright 1980, Endler 1981, Robinson 1981). Most ecologists define 'habitat mimicry' as the resemblance of an organism to a discrete part of its habitat, while 'camouflage' refers to cases where an organism 'blends' into or looks like its habitat by resembling a mosaic of habitat patterns. Most often such effects have been achieved visually, by resemblance to habitat morphology (shape and size), color, or by behaving so as to remain inconspicuous in the habitat. In some cases, chemical, auditory, and olfactory signals are also important (Czaplicki et al. 1975, Eberhard 1977, Fenton \& Fuller 1981, Cloudsley-Thompson 1981). The confusion in terminology comes from a disagreement about whether animals that mimic habitat structures [e.g plant-part mimics (sensu Robinson 1970)] are perceived by predators in the same way as animals that camouflage themselves in their habitat. Some ecologists (Endler 1981, Robinson 1981) believe that cryptic animals send few or no signals that predators can recognize as prey. Animals that mimic their habitat, on the other hand, send false signals to the predator that 'trick' the predator into detecting the prey as something other than prey, e.g. a stick or stone, which they ignore. However, Vane-Wright (1980, p. 3) has written that both types of resemblance should be placed together since predators filter out information on habitat components because '[they] are not looking for leaves, sticks, grass or bark-like objects to eat, they are looking for insect-like objects, using some general cognitive 'model' of an insect as a search-image'.

While this debate will not be settled until more is known about how predators perceive and integrate information about prey, there appear to be at least a few reasons to separate mimicry from camouflage. As this study shows, the morphology, coloration and behavior of cryptic and mimic shrimps that are close taxonomically (in the same family, Hippolytidae) can be quite different, suggesting different ecological and evolutionary results to predation pressure within the same habitat. In addition, the use of camouflage or mimicry may vary, depending on the ontogenetic stage of the prey, so that within the lifetime of an individual these 2 types of resemblance are used in different ways to hide from predators. We will, therefore, use the definitions of Endler $(1978,1981,1984)$ and Robinson (1981) because of their ecological relevance to this paper. Camouflage is defined as an organism resembling in color pattern the mosaic of patches or spots of varying sizes, shapes, colors, and brightnesses of its habitat such that the predator does not perceive the prey against the background. Habitat mimicry is defined as an organism resembling, in size, shape, color and behavior, a particular structural component of the habitat so as to avoid being recognized as prey.

Two species of decapod shrimps, Latreutes fucorum (Fabricius) and Hippolyte coerulescens (Fabricius) (hereafter referred to by genus), were used in this study. While Hippolyte is only found associated with pelagic Sargassum, Latreutes is common in both Sargassum and seagrass meadows in the tropical Atlantic (Williams 1984, Leber 1985). Both species are well known for their ability to cling to their algal habitat (Gurney 1936, Brown 1939). Morphologically, these 2 species are distinct. Latreutes is thin both in the carapace and abdomen when compared to Hippolyte which has a globose carapace and abdomen (Fig. 1A, D). They both range from colorless and transparent, to yellow, brown, and black, sometimes with spots or stripes of white, brown or bright blue (Fig. 1). Latreutes is usually a solid color but may have stripes or spots of contrasting colors parallel or perpendicular to its body corresponding in pattern to irregularly colored bits of weed' (Williams 1984) (Fig. 1B). Hippolyte has either a solid-colored body or is 'banded with brownish yellow in such a way that it seems to be broken up into 2 parts (cephalothorax-abdomen), each of which looks very like a vesicle of Sargassum' (Gurney 1936) (Fig. 1D, E).

These shrimps have many fish predators that either live in the Sargassum plants or in the surrounding water (Adams 1960, Dooley 1972). One important predator on shrimps is the Sargassum fish Histrio histrio (Linnaeus) (hereafter referred to by genus), a remarkable camouflaged predator that lives in pelagic 

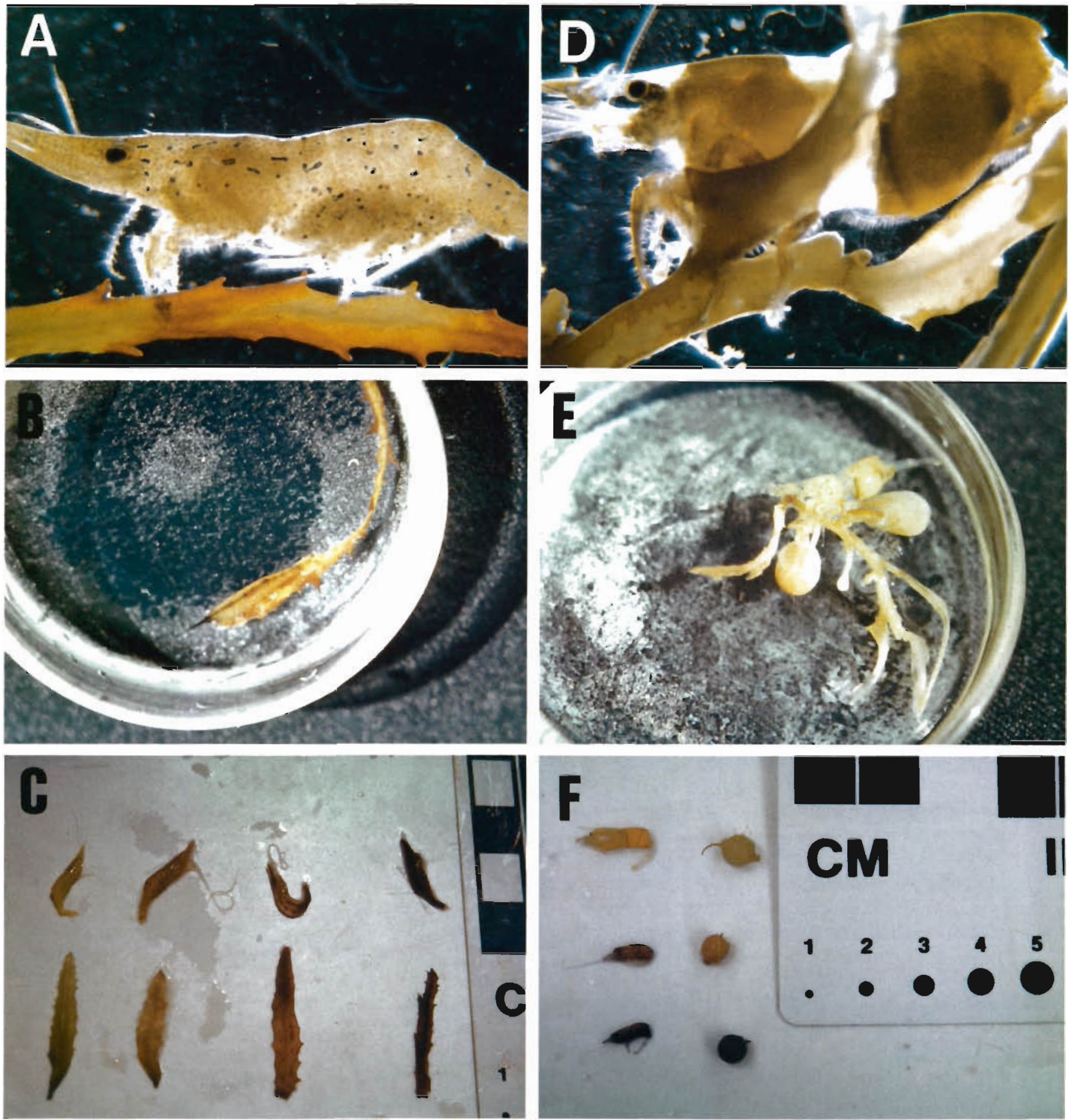

Fig. 1. Latreutes fucorum and Hippolyte coerulescens. Camouflage and mimicry in shrimps living in Sargassum. (A) Latreutes, size $=20 \mathrm{~mm}$, magnification $=4 X_{;}$(B) a Latreutes clinging to Sargassum frond; (C) range of color variation of small Latreutes and Sargassum fronds; (D) Hippolyte, size $=25 \mathrm{~mm}$, magnification $=4 \times$; (E) a Hippolyte clinging to main stalk of Sargassum;

(F) range of color variation in small Hippolyte and Sargassum vesicles

Sargassum. Although little is known about the ecology of Histrio, gut analyses (Dooley 1972, Smith 1973) and an energetic study (Smith 1973) have shown that they are voracious predators on Sargassum crustaceans.
In this study we have used some of the anecdotal information about Sargassum shrimps (Gurney 1936, Brown 1939, Sisson 1976, Williams 1984) along with measurement techniques and experimental methods 

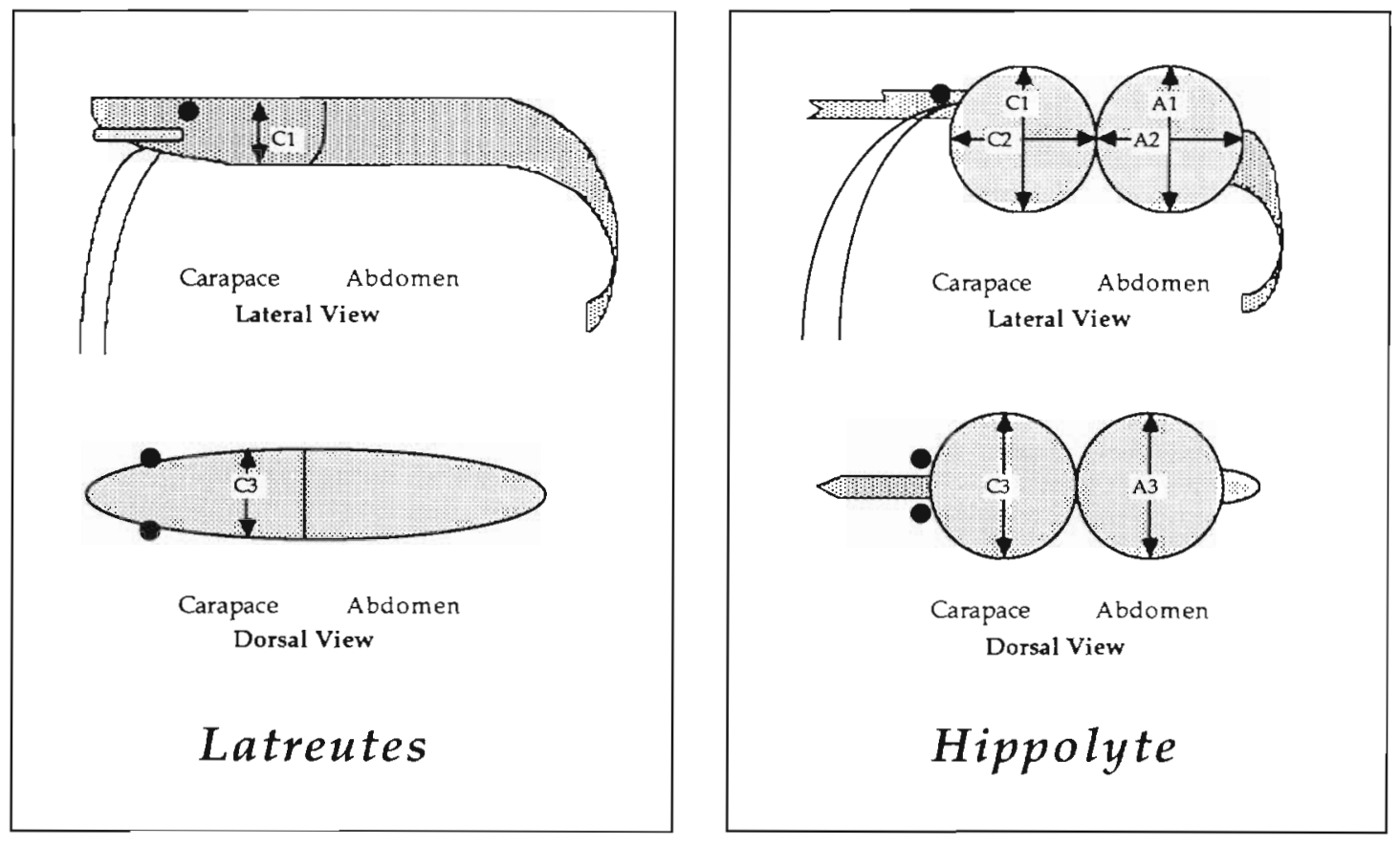

Fig. 2. Latreutes fucorum and Hippolyte coerulescens, showing where measurements of the body dimensions were made. C1 = lateral width of carapace, C2 = lateral length of carapace, C3 = dorsal width of carapace, A1 = lateral width of abdomen, A2 = lateral length of first 3 abdominal segments, $A 3=$ dorsal width of abdomen

used recently by Hacker \& Steneck (1990), to show that the morphology, color, and behavior of these shrimps maximizes their resemblance to Sargassum. We measured components of the body size of the 2 species of shrimps and of the habitat architecture of Sargassum to discover whether these shrimps are scaled in size and shape with their habitat. Behavioral observations as well as habitat selection experiments using Sargassum and plastic artificial algae of different habitat architectures and colors were performed with the shrimps. The importance of predation to camouflage and mimicry is discussed in relation to the shrimps and fishes found in Sargassum collections from this study.

\section{METHODS}

Field collections. Individual plants of Sargassum were collected southeast of Bermuda $\left(31^{\circ} \mathrm{N} 64^{\circ} \mathrm{W}\right)$ in the Sargasso Sea during a cruise aboard the RV 'Gyre' (19 March to 12 April 1990). Although there are 2 species of pelagic Sargassum in the Sargasso Sea, $S$. natans and $S$. fluitans Boergesen, only $S$. natans was used in this study because it constituted ca $94 \%$ of all Sargassum collected. Sargassum was collected, either by SCUBA divers or from a small boat, by placing plastic 'zip-lock' bags over individual plants and sealing them before animals could escape. Care was taken to include only one individual plant per bag and to disturb the animals in the Sargassum as little as possible. Samples were preserved in $5 \%$ buffered formalin, poured through a $250 \mu \mathrm{m}$ mesh sieve to separate the animals from the algae, and stored in $70 \%$ ethanol before counting.

All crustaceans and fish in the samples were identified to species and counted. In addition, measurements of Latreutes and Hippolyte body sizes and shapes were made using either a dissecting microscope (fitted with an ocular reticle) or a ruler. The total length $(\mathrm{mm})$ and other dimensions of both the dorsal and Iateral sides of the shrimps were measured (Fig. 2). For Latreutes, we measured 2 dimensions (C1, C3) of the carapace as shown in Fig. 2 since this was the widest and thickest point on the shrimp. For Hippolyte, we measured 3 dimensions of the carapace (C1, C2, C3) and abdomen [A1, A2 (first 3 abdominal segments), A3] as shown in Fig. 2.

Laboratory observations and experiments. Shrimps used in observations or experiments were collected from clumps of Sargassum captured from the surface water using a fine mesh dip-net. Once the shrimps were picked out of the algae, they were transferred directly to tanks for observation or experimental trials.

Behavioral observations of shrimps in Sargassum were made in the ship's laboratory. Ten individuals of Latreutes and Hippolyte were each placed separately 

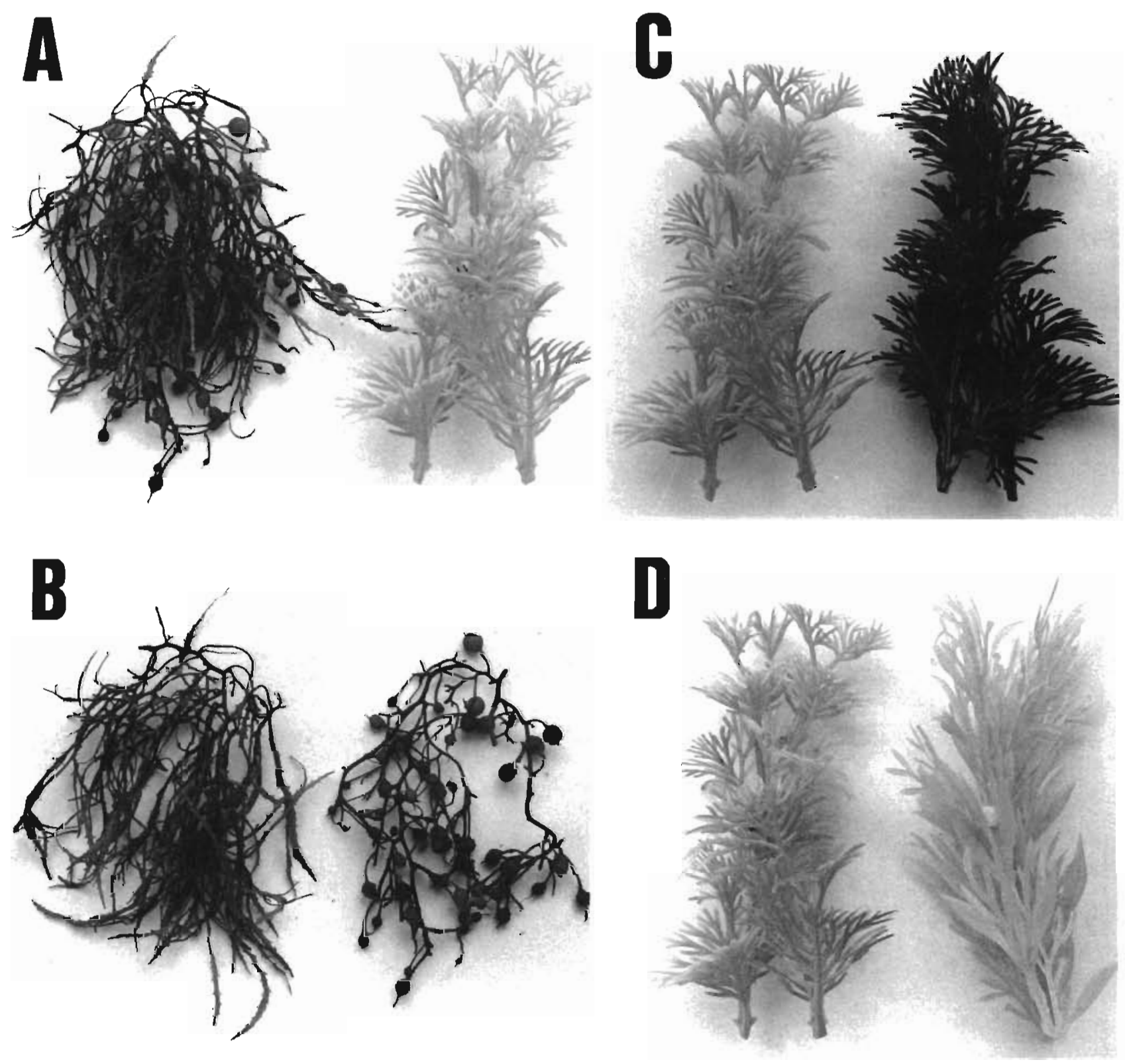

Fig. 3. Sargassum natans and artificial algae. Types of plant pairs (length $=10 \mathrm{~mm}$ for each plant) used in the 4 habitat selection experiments (see 'Methods: Laboratory observations and experiments'). (A) Sargassum (left) and artificial algae (right) used in Expt 1; (B) Sargassum with 'fronds only' (left) and 'vesicles only' (right) used in Expt 2; (C) yellow (left) and brown (right) artificial algae used in Expt 3; and (D) small- (left) and large-frond (right) artificial algae used in Expts 4 and 5

in 61 of seawater in a glass tank $(11 \times 30 \times 30 \mathrm{~cm})$ that allowed easy observation. Water was changed in the tank between each period of observation so that temperature was kept at 18 to $20^{\circ} \mathrm{C}$. Observational periods lasted $20 \mathrm{~min}$ each and the duration of each behavior was timed to the nearest minute. The following behaviors were identified and timed: (1) clinging parallel to a frond; (2) clinging perpendicular to a branch; (3) clinging to a vesicle; (4) swimming; and (5) rare behaviors that included preening, movement around the frond, caridean tail-flip response, and 'walking' on the blade.

Habitat selection experiments were conducted on the deck of the ship (exposed to normal light conditions) in 2.81 cylindrical glass jars equipped with sealed lids, and connected to a continuous flow of surface seawater through tubing attached to the lid. Water temperature $\left(18\right.$ to $\left.20^{\circ} \mathrm{C}\right)$ in the jars was approximately the same as that of the surface water.

Five different habitat selection experiments were 
conducted in 8 separate tanks. In each experiment, 2 habitat options of equal size $[150 \mathrm{ml}$ canopy volume (defined in 'Methods: Measurement of algal habitat')] were presented to 6 shrimps of the same species and approximate size (Latreutes length range $=13$ to $17 \mathrm{~mm}$ i except see Expts 4 and 5 below; Hippolyte length range $=10$ to $18 \mathrm{~mm}$ ). In all experiments, plants were used only once. Plants were allowed to float at the top of the tanks to simulate natural conditions of pelagic algae, and shrimps were introduced into the middle of the tank. Trials were allowed to run for $10 \mathrm{~h}$ between 23:00 and 09:00 h ADT. Each plant was removed from the tank using forceps, and the shrimps were picked off and processed as described for field collections. Each time a plant was removed from the tank it was visually inspected for shrimps that might swim out of the plant before they could be counted. This occurred 3 times and the shrimps were included in the count of total shrimps found on that plant. Each experiment had from 6 to 8 replicate trials (see description of experiments below and figures for the actual sample size). Since there were 6 shrimps per trial and up to 8 trials per treatment, the experiment ran for $10 \mathrm{~h}$, and the plants were in close proximity to each other in the tanks, it is likely that both plants were sampled equally by the shrimps before a habitat choice was made. The experiments were as follows:

- Expt 1, Sargassum versus artificial algae (Fig. 3A): To test whether Latreutes and Hippolyte would choose artificial algae, one Sargassum plant and one smallfrond yellow plastic aquarium plant were used in 6 replicate habitat selection trials for each shrimp species.

- Expt 2, Sargassum with 'fronds only' versus Sargassum with 'vesicles only' (Fig. 3B): To test whether Latreutes and Hippolyte choose habitats based on the shape of the plant parts, one individual Sargassum plant clipped to remove all the vesicles and the other to remove all the fronds was used in 6 (Hippolyte) and 7 (Latreutes) replicate trials.

- Expt 3, yellow artificial algae versus brown artificial algae (Fig. 3C): To test if there is a preference for algal color, Latreutes and Hippolyte were allowed to choose between small-frond plastic aquarium plants colored brown and yellow in 7 replicate trials for each shrimp species.

- Expt 4, artificial algae with 2 architectures, one with small fronds and one with large fronds (Fig. 3D): To test whether small [ 6 to $15 \mathrm{~mm}$ total length (TL)] or large (>15 mm TL) size individuals of Latreutes prefer habitats with small or large fronds, 2 yellow plastic aquarium plants with different frond lengths and widths were used in 8 replicate habitat selection trials for each shrimp size.

- Expt 5, the same as Expt 4, except with a fish predator (Fig. 3D): To test whether the presence of a predator will influence the habitat choice of Latreutes given the conditions in Expt 4, single fish [Histrio histrio was chosen since it was the only fish found in our samples (see 'Results: Patterns of abundance, size scaling and behavior')] ranging in size from 25 to 35 $\mathrm{mm}$ total length were placed in the tank in a clear plastic exclusion cage with holes so that only water could pass in and out of the cage.

Measurement of algal habitat. Methods used to measure the habitat architecture of Sargassum and artificial algae were adapted from those of Hacker \& Steneck (1990). Volumetric measurements of the algae are used instead of weight measurements, since habitat architecture is a measure of both the structural and spatial components of a habitat. These measurements have advantages over algal weights since they allow animal densities to be expressed in terms of the volume of water-filled spaces between the algal thallus in which they reside. Volumetric measurements were made of all the samples of Sargassum plants and of the artificial plants. Canopy volume $(\mathrm{CV})$ is the volume (ml) defined by the length, width and height $(\mathrm{cm})$ of a plant submerged in water. Thallus volume (TV) is the volume (ml) of the algal thallus measured by placing the alga in water and determining the volume by displacement. Interstitial volume (IV) is the volume (ml) of water taken up by the spaces between the canopy of the alga; it is determined by subtracting the thallus volume from the canopy volume. Significant positive regressions of $\mathrm{CV}$ to TV $\left(\mathrm{TV}=405.0+231.3 \mathrm{CV}, \mathrm{r}^{2}=0.79, \mathrm{p}=0.001\right)$ and $C V$ to algal dry weight (DW; g) (DW $=559.5+25.8$ $\mathrm{CV}, \mathrm{r}^{2}=0.83, \mathrm{p}=0.001$ ) for Sargassum show that measurements of canopy volume are predictive and reliable measures of algal habitat.

Only the structural components of the habitat were measured in this study because the shrimps mimic the structures of Sargassum rather than the spaces between fronds and vesicles. The space size did not limit small or large shrimps from residing on the algae or artificial algae (see 'Results') as has been shown for amphipods (Hacker \& Steneck 1990).

To determine the structural components of the plants, samples of Sargassum and artificial algae were measured in 2 dimensions. Twelve individual plants of Sargassum with thallus volumes of 0.5 to $1.9 \mathrm{ml}$ were floated in water on top of a glass plate, which was raised from underneath so that the algae were positioned on the plate in 2 dimensions as they would be if floating. Another glass plate was placed on top along with a ruler for scale, and the 'sandwich' was photocopied. The stiff artificial algae was not pressed between plate glass since it did not photocopy well under this treatment and only one plant of each type [small- and large-frond (Fig. 3D)] was used because the 
Table 1. Abundance of crustaceans and fish in 26 plants of pelagic Sargassum natans collected between 19 March and 12 April 1990 at $31^{\circ} \mathrm{N} 64^{\circ} \mathrm{W}$ in the Sargasso Sea. Species A is significantly different from all species represented by B (1- way ANOVA, $\mathrm{p}<0.001 ;$ Student-Neumann-Keuls, $\mathrm{p} \leq 0.05$ )

\begin{tabular}{|lcc|}
\hline Crustaceans & \multicolumn{2}{c|}{ No. per 5 l interstitial volume } \\
& Mean $\pm \mathrm{SD}$ & $\mathrm{SNK}$ \\
\hline Sunamphitoe pelagica (Bate) (amphipod) & $42.9 \pm 30.9$ & $\mathrm{~A}$ \\
Latreutes fucorum (Fabricius) (shrimp) & $4.1 \pm 3.9$ & $\mathrm{~B}$ \\
Planes minutus (Linné) (crab) & $2.5 \pm 0.5$ & $\mathrm{~B}$ \\
Hippolyte coerulescens (Fabricius) (shrimp) & $1.7 \pm 4.1$ & $\mathrm{~B}$ \\
Leander tenuicornis (Say) (shrimp) & $0.1 \pm 0.2$ & \\
Fish & No. per 20 l interstitial volume \\
\hline Histrio histrio (Linnaeus) & Mean $\pm \mathrm{SD}$ & \\
\hline
\end{tabular}

Table 2. Latreutes fucorum and Hippolyte coerulescens. Dimensions of (A) carapace (C1, C2, C3 illustrated in Fig. 2) and (B) abdomen (A1, A2, A3 illustrated in Fig. 2). A comparison (C) between the mean carapace and mean abdomen dimensions is given for Hippolyte. NM: not measured

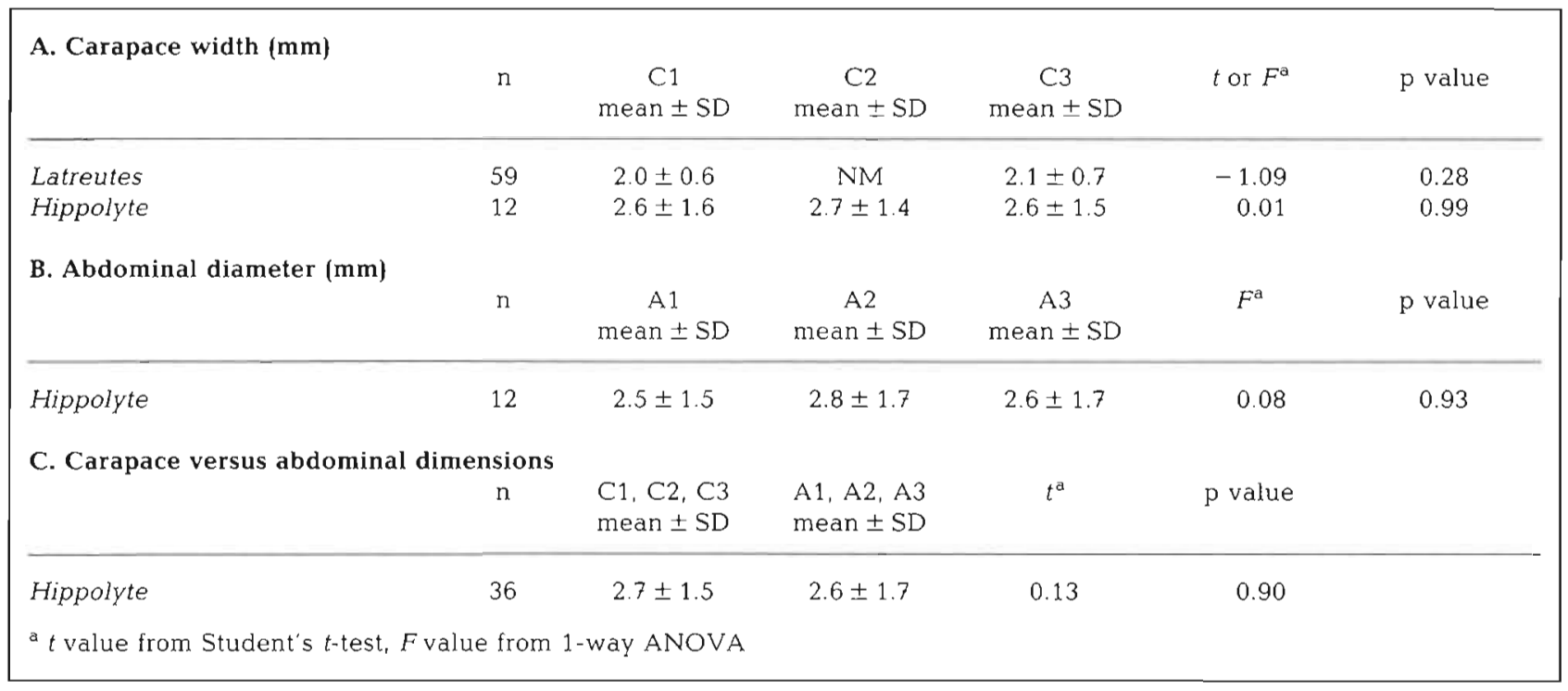

artificial algae were all identical. The structural components measured included the number, length and width of fronds, and the number and diameter of vesicles. The widths and diameters were measured at their widest point on the fronds and vesicles. The arrangement of fronds or vesicles was not measured.

\section{RESULTS}

\section{Patterns of abundance, size scaling and behavior}

The abundance of crustaceans and fish found in Sargassum clumps is given in Table 1. A species of amphipod, Sunamphitoe pelagica Bate, was signifi- cantly more abundant than any other crustacean in Sargassum (Table 1). The abundances of 4 species of decapods, Latreutes, Hippolyte, Leander tenuicomis (Say), and Planes minutus (Linné) are given in Table 1. There was no significant difference between them. $P$. minutus was the only species of decapod crab found in the collection samples, although Portunus sayi (Gibbes) was found twice while collecting shrimp for experimental trials. The Sargassum fish Histrio was the only fish found, with ca 1 per 201 of interstitial volume (equal to ca 1 per 6 individual plants).

Shrimp body dimensions (Fig. 2) were measured to determine the size and shape of the 2 species of shrimps so that they could subsequently be related to Sargassum structural components (Table 2). Latreutes 
carapace dimensions measured at the lateral (C1) and dorsal (C3) sides did not significantly differ (Table $2 \mathrm{~A}$ ). For Hippolyte, the carapace and abdomen are approximately spherical since the dimensions $\mathrm{C} 1, \mathrm{C} 2$, and $\mathrm{C} 3$, and $A 1, A 2$, and $A 3$ are not significantly different (Table $2 A, B$ ). When the mean of all the diameter measures for the carapace was tested against the abdomen measurements, there was no significant difference (Table 2C), so only the dorsal carpace widths are used in subsequent analyses. Regressions of length (L) in $\mathrm{mm}$ to dorsal carapace width (W) in $\mathrm{mm}$, the length range and the mean length for both species are as follows: Latreutes, $\mathrm{W}=0.11 \mathrm{~L}^{1.12}, \mathrm{r}^{2}=0.80, \mathrm{n}=193$, length range $=5$ to $20 \mathrm{~mm}$, mean length $\pm \mathrm{SD}=14.4$ \pm 2.9; Hippolyte, $\mathrm{W}=0.13 \mathrm{~L}^{1.15}, \mathrm{r}^{2}=0.86, \mathrm{n}=49$, length range $=6$ to $23 \mathrm{~mm}$, mean length $\pm \mathrm{SD}=14.0$ \pm 4.2 .

The habitat structural components of Sargassum are compared to the body size dimensions of Latreutes and

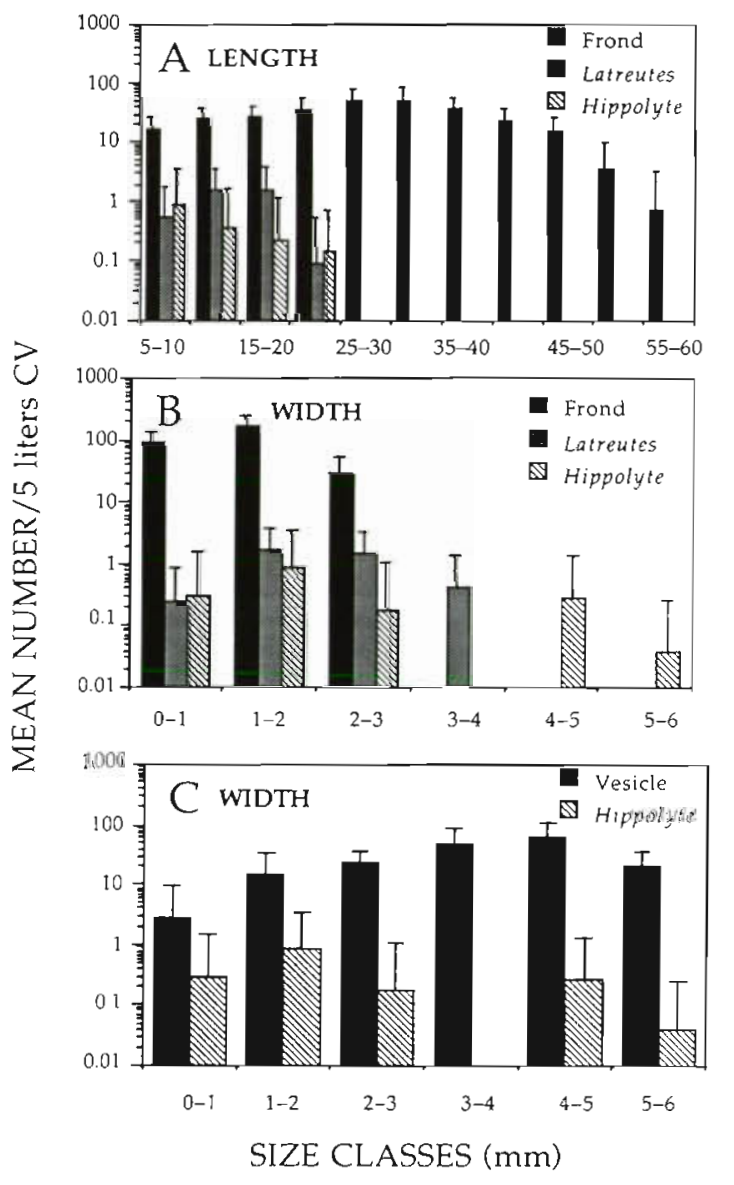

Fig. 4. Frequency distributions of Latreutes fucorum $(\mathrm{n}=193)$, Hippolyte coerulescens $(n=49)$, and the structural components of Sargassum natans ( $\mathrm{n}=12$ ). Plots show the mean number per 51 canopy volume (CV) of (A) lengths of fronds and shrimps, $(B)$ widths of fronds and shrimps and (C) diameters of vesicles and Hippolyte carapace (dimension C3). Vertical bars are $\pm 1 \mathrm{SD}$
Hippolyte in Fig. 4. Length-frequency of Sargassum fronds is compared to the frequency of Latreutes and Hippolyte total body lengths in Fig. 4A. The fronds ranged from 5 to $60 \mathrm{~mm}$ in length, and both species of shrimps were shorter than most of the fronds, ranging from 5 to $25 \mathrm{~mm}$ in length (Fig. 4A). The width of Sargassum fronds varied from $<0$ to $3 \mathrm{~mm}$ (Fig. $4 \mathrm{~B}$ ). Latreutes carapace widths corresponded to most of the frond widths, but there was one size class that had individuals $1 \mathrm{~mm}$ wider than the widest fronds of Sargassum. Some Hippolyte individuals corresponded to the size classes of Sargassum fronds but they ranged up to $6 \mathrm{~mm}$ in width, $3 \mathrm{~mm}$ more than the widest fronds. Finally, the vesicle diameters of Sargassum are compared to the dorsal carapace diameters of Hippolyte in Fig. 4C. The carapace diameters of the shrimp are in the same range as the diameters of the vesicles, except for the absence of shrimp in the 3 to $4 \mathrm{~mm}$ size class.

The shapes of the 2 species of shrimps are quite different (Figs. 1, $2 \& 4$; Table 1). While both species are the same length (Fig. 4A), Latreutes has equal dorsal and lateral widths that are about $15 \%$ of their total body length, while Hippolyte has a spherical carapace and abdomen that are equal in size (Table 2C) and about $20 \%$ each of their total body length (calculated from regressions given previously). Latreutes has a long, thick tapered rostrum and tapered abdomen simi-

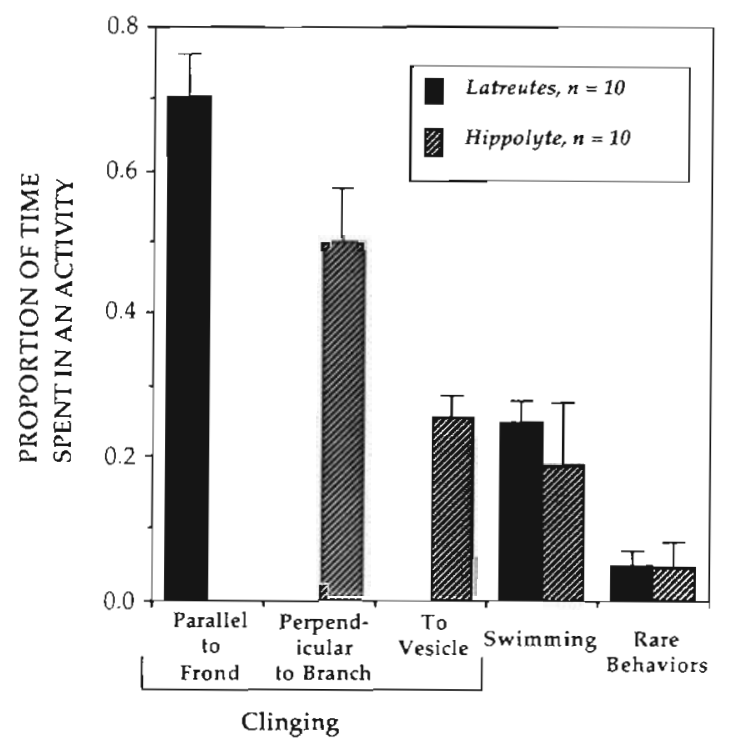

Fig. 5. Latreutes fucorum and Hippolyte coerulescens. Behavioral activities in their Sargassum habitat. The proportion of time spent in each activity is calculated by dividing the total time spent in that activity by the total observation time. A 2-way fixed-factor ANOVA showed that both species spend signifcantly more time clinging to Sargassum than in any other behavior (see 'Results: Patterns of abundance, size scaling and behavior' for statistical summary). Rare behaviors included preening, movement around the frond, caridean tailflip response, and 'walking' on the blade 
lar to the tapered ends of Sargassum fronds (Fig. 1A, B, C). The 4 th, 5 th, and 6 th abdominal segments of Hippolyte are much thinner than the first 3 segments composing the spherical abdomen, and resemble the hooked spur- or leaf-like projection on the end of vesicles of Sargassum natans (Fig. 1D, E, F).

The mean proportion of time spent in an activity or behavior while in the Sargassum is given in Fig. 5 for Latreutes and Hippolyte. The behaviors were initially classified as clinging, swimming and rare behaviors. A 2-way fixed-factor ANOVA of species and behavior showed the species factor to be insignificant $(F=0.03$, $\mathrm{p}=0.87$ ) and the behavior factor to be significant $(F=$ $813.90, \mathrm{p}=0.001)$. There was a significant interaction between these 2 factors $(F=3.48, \mathrm{p}=0.04)$. A StudentNewman-Keuls multiple comparisons test revealed that there was a significant difference in the proportion of time spent in different behaviors for both species, with the proportion of time spent clinging being significantly more than that of swimming or rare behaviors $(\mathrm{p} \leq 0.05)$. There was no difference between species in

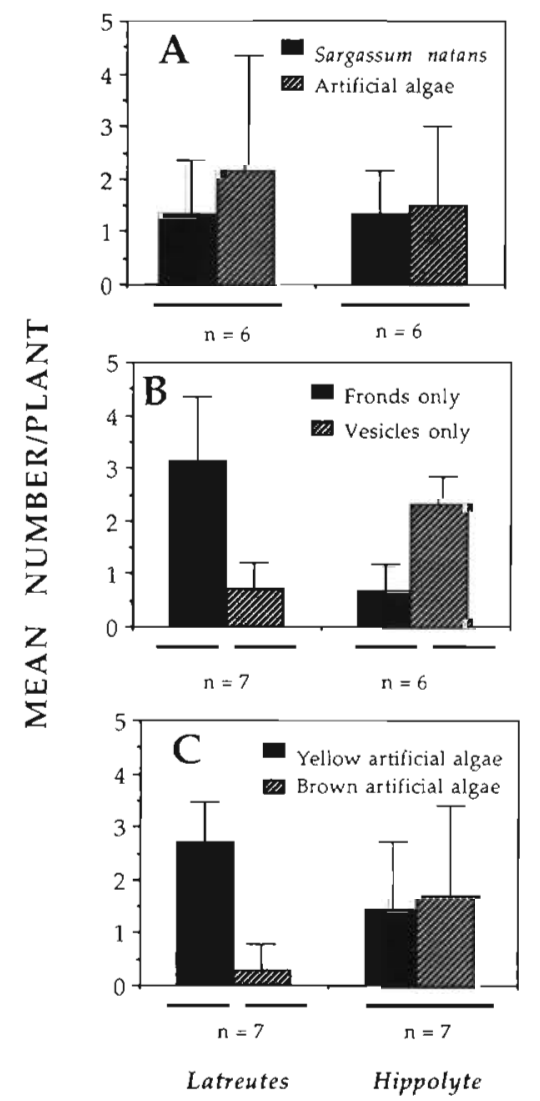

Fig. 6. Latreutes fucorum and Hippolyte coerulescens. Habitat selection experiments. Mean number of shrimps per plant $(150 \mathrm{ml}$ canopy volume) in (A) Sargassum vs plastic algae, (B) Sargassum with 'fronds only' vs 'vesicles only', and (C) yellow vs brown artificial algae. Vertical bars are $\pm 1 \mathrm{SD}$. Breaks in horizontal lines for each species of shrimp represent significance at $\mathrm{p} \leq 0.05$ (Mann-Whitney $U$ ) the time spent in a particular behavior. When the clinging behavior is examined in more detail, Latreutes only clings parallel to a frond, while Hippolyte only clings perpendicular to a branch or to a vesicle (Fig. 5).

\section{Process of habitat selection}

The results of experiments to test what choices the 2 species of shrimps made among habitats of different architectures and colors are given in Fig. 6. There was no significant difference in the density of Latreutes on Sargassum or the artificial algae (Mann-Whitney $U$ test, $\mathrm{p}=0.36, \mathrm{n}=6$; Fig. $6 \mathrm{~A}$ ). The same was true for Hippolyte (Mann-Whitney $U$ test, $\mathrm{p}=0.49, \mathrm{n}=6$; Fig. 6A). However, there was a significant difference in the density of Latreutes on Sargassum fronds versus vesicles (Fig. 6B). The highest density of Latreutes was found on the algae with 'fronds only' and the lowest on algae with 'vesicles only' (Mann-Whitney $U$ test, $\mathrm{p}=$ 0.02, $\mathrm{n}=7$; Fig. 6B). The opposite was true for Hippolyte, with significantly more individuals on the algae with 'vesicles only' compared to the algae with 'fronds only' (Mann-Whitney $U$ test, $\mathrm{p}=0.05, \mathrm{n}=6$; Fig. 6B). Finally, significantly more Latreutes were found on the yellow artificial algae than on the brown artificial algae (Mann-Whitney $U$ test, $\mathrm{p}=0.04, \mathrm{n}=7$; Fig. 6C); Hippolyte was found in equal numbers on both colors (Mann-Whitney $U$ test, $\mathrm{p}=0.50, \mathrm{n}=7$; Fig. 6C) .

Fig. 7 shows the size of structural components of the artificial algae (see Fig. 3D). Size-frequency distributions show that the small-frond artificial algae have a higher frequency of smaller size classes of frond lengths and widths than do the large-frond artificial algae which have a higher frequency of larger size

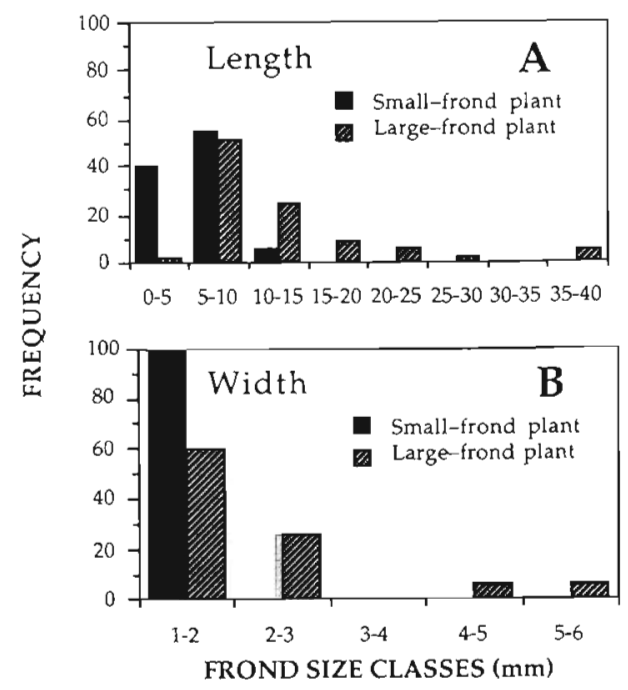

Fig. 7. Size-frequency plots of the $(A)$ length $(n=1)$ and $(B)$ width ( $n=1$ ) of small- and large-frond artificial algae 
classes of frond lengths and widths (Fig, 7 A, B). Smallfrond algae also had 3.6 times more fronds (864 fronds per $100 \mathrm{ml} \mathrm{CV}$ ) compared to the large-frond plants (240 fronds per $100 \mathrm{ml} \mathrm{CV}$ ). Statistical tests could not be done on these data because only one artificial plant of each type was measured.

Results of the size-scaling experiment for Latreutes with and without an enclosed predator are shown in Fig. 8. In the absence of a predator, the 2 different size classes of Latreutes responded differently to the 2 artificial plants. Small Latreutes were found in significantly higher densities on the small-frond artificial algae than on the large-frond artificial algae (Mann-Whitney $U$, $\mathrm{p}=0.05, \mathrm{n}=8$; Fig. 8A), but large Latreutes were found in equal densities on both habitats (Mann-Whitney $U, \mathrm{p}=0.48, \mathrm{n}=8 ;$ Fig. $8 \mathrm{~A}$ ). The same was true for shrimp in the presence of an enclosed predator; small Latreutes were found in significantly higher densities on the small-frond artificial algae than on the largefrond artificial algae (Mann-Whitney $U, \mathrm{p}=0.05, \mathrm{n}=5$; Fig. 8B), but large Latreutes were found in equal densities on both habitats (Mann-Whitney $U, \mathrm{p}=0.49$, $\mathrm{n}=5$, Fig. $8 \mathrm{~B}$ ).

\section{DISCUSSION}

\section{Size, color and behavioral responses of shrimps to habitat dimensions}

The 2 species of Sargassum shrimps studied have different morphologies that correspond to specific structural components of pelagic Sargassum (Fig, 4), and different behaviors that keep them associated with those structures (Fig. 5). Almost all the size classes of Latreutes corresponded to the size and shape of Sargassum fronds (Fig. 4A, B). Hippolyte resembled the size and shape of Sargassum vesicles (Fig. 4C). The range of frond lengths exceeded that of shrimp lengths for both species (Fig. 4A). There were fronds as wide as all but the largest class of Latreutes, but the larger Hippolyte were as much as $3 \mathrm{~mm}$ wider than the widest Sargassum frond (Fig. 4B). The inconsistency in size scaling for large Latreutes was also seen in the scaling experiment (Fig. 8). While small Latreutes were found in highest densities on small-frond artificial algae, large shrimp did not show a preference for the largefrond size, even though all fronds of the small-frond artificial algae were shorter and thinner than these shrimp (Fig. 7A, B). Although comparable size scaling experiments were not done for Hippolyte, analysis of the diameters of the carapace and abdomen showed that almost all the shrimp had corresponding sizes of vesicles (Fig. 4C).

Although morphological resemblance is very impor-

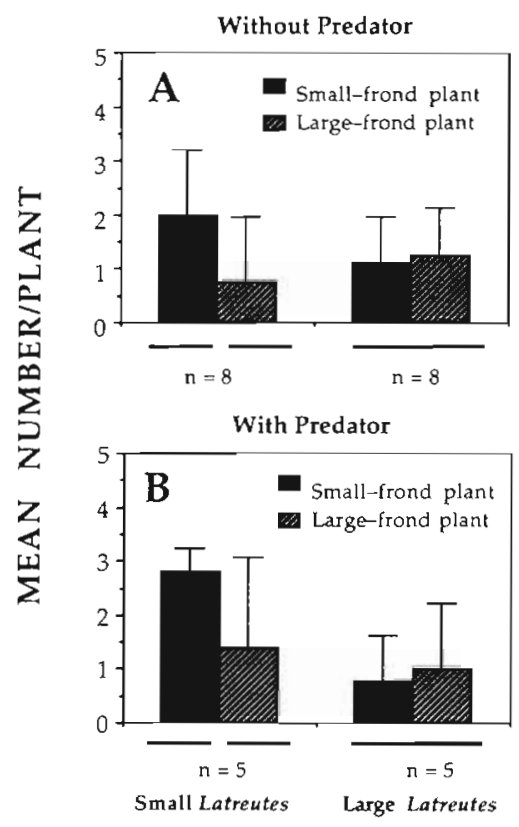

Fig. 8. Latreutes fucorum. Size scaling experiments. Mean number of shrimp per plant (150 $\mathrm{ml}$ canopy volume) in smallvs large-frond plastic plants (A) without a fish predator and (B) with an enclosed fish predator. Vertical bars are $\pm 1 \mathrm{SD}$. Breaks in horizontal lines for each size of shrimp represent significance at $p \leq 0.05$ (Mann-Whitney $U$ )

tant, similar coloration of an animal with its habitat is an integral part of camouflage and mimicry. Latreutes can be either banded, striped and spotted with mixtures of 4 pigment colors (white, red, yellow, and blue) (Fig. 1A, B; Brown 1939), or simply solid-colored or transparent (Fig. 1C; Brown 1939). Smaller Latreutes tend to be transparent or solid-colored, while larger Latreutes have much more color pattern development. Small Hippolyte are usually solid-colored (Fig. 1F), and larger individuals have a transparent band separating the spherical carapace and abdomen (Fig. 1D, E; Gurney 1936). The rostrum, antennae, last 3 abdominal segments, uropods and telson are all transparent, adding to the spherical appearance of the carapace and abdomen (Fig. 1D, E, F).

Besides the differences described above in body color and pattern, Latreutes and Hippolyte showed differential responses to the colored plastic habitats. Latreutes preferred the yellow to the brown artificial algae, while Hippolyte showed no preference between the 2 colors (Fig. $6 \mathrm{C}$ ). The possibility of size-dependent body color and habitat choice needs to be explored. We do not know the distribution of colors and patterns in the field for the 2 species at different sizes, and whether the results of color manipulation experiments might vary for different-sized shrimps. Experiments will need to control for shrimp color, as well as shrimp size and species, to obtain a clear idea 
of what processes may be driving this differential habitat choice.

Color variation with size has been reported for Heptacarpus sp. (Bauer 1981), a shrimp in the same family (Hippolytidae) as Latreutes and Hippolyte. In Bauer's study, small shrimp tended to be transparent and larger ones had well-developed color patterns. The shrimp that were not solid-colored had a pattern of disruptive coloration (sensu Cott 1957). This presumably disrupts the outline of the shrimp so that it blends into the visual mosaic of the habitat. It has been suggested (Cott 1957 , Bauer 1981) that bold longitudinal stripes break up an animal's form into 2 apparently unconnected parts; predators that use bilateral symmetry to recognize prey might be deceived by a longitudinal stripe that disrupts this symmetry (Robinson 1969). It seems likely that the banding, spots, or transparency between the carapace and abdomen seen for Latreutes and Hippolyte may also serve this disruptive function.

In addition to resembling the size, shape and color of fronds and vesicles, Latreutes and Hippolyte behaved so as to remain positioned like fronds and vesicles. Latreutes spent ca $70 \%$ of its time clinging parallel to the fronds of Sargassum (Figs. 1B \& 5) and preferred 'fronds only' plants to 'vesicles only' plants (Fig. 6B).

Hippolyte characteristically oriented itself perpendicular to the main stalk of the Sargassum (Figs. 1E \& 5) or grasped the vesicles, and preferred a 'vesicles only' alga to a 'fronds only' one (Fig. 6B). Hippolyte may have the capability of recognizing and choosing vesicles instead of fronds. Interestingly, a congener, $H$ californiensis, which lives in seagrass meadows, has been shown to have sophisticated capabilities of shape recognition (Barry 1974), preferring long, thin, vertical shapes arranged in specific patterns that resemble seagrass to other shapes offered.

\section{General versus specific resemblance}

It is apparent that the 2 species of shrimps, and possibly different-sized individuals of the same species, resemble different parts of their common habitat. It may be that there is an ontogenetic shift from plantpart mimicry to camouflage as the shrimps get larger. As the shrimps outgrow the specific plant parts they mimic, they must use color patterns to camouflage themselves and generally resemble the larger Sargassum habitat matrix. Small Latreutes and Hippolyte individuals mimic specific structural components of the Sargassum, aided by their solid color and small size. Preferential use of small-frond algal mimics by small Latreutes in the presence or absence of a predator (Fig. 7) supports this hypothesis; however, a functional inability to grasp large fronds may also be a factor. As
Hippolyte individuals get larger and outgrow the size of single vesicles, they use disruptive coloration to break up the outline of their body so they continue to resemble a pair of vesicles.

Large Latreutes, on the other hand, may be camouflaged in their hatitat. As Latreutes grows too large to match single fronds, diverse patterns of coloration to disrupt their body shape and resemble the random mosaic of different-colored fronds and the open spaces between them become more important. In fact, the bright blue spots on large Latreutes may resemble open patches of water between Sargassum fronds and vesicles (Fig. 1A). The fact that large shrimp do not prefer small- or large-frond mimics even when a predator is present suggests that they no longer seek to hide on fronds of a particular size, but depend on camouflage to resemble the habitat in general.

This study suggests that mimicry of specific habitat parts may change to camouflage based on general resemblance of the habitat as the shrimp grows, and that different methods of measurement are required to characterize these 2 kinds of resemblance. We concentrated on comparing dimensions of the structural components of the habitat with shrimp body size, shape and coloration, but made no measurements to quantify the disruptive color patterns of large shrimps that seem to match the mosaic of patterns in the Sargassum habitat. In contrast, Endler (1984) measured general resemblance of moths to the background of a deciduous forest by quantifying the mosaic of patches of different-colored leaves and spaces between leaves and correlating this to moth coloration. Components of specific resemblance, or mimicry, were not measured as they were in our study. While many moth species did correlate with measurements of general resemblance, other moth species that mimicked plant parts did not. Endler points out that 'One of the main differences [between crypsis and mimicry] is that the overall body shape and the shapes of the color pattern elements are important in special, but not general resemblance. The presence of specific resemblance makes quantification of crypsis difficult' (Endler 1984, p. 220).

The dividing line between mimicry and camouflage is often confused. Vane-Wright (1980) noted that '. . . as it is unlikely that any satisfactory method for 'objectively' measuring degree of morphological specialization can be devised, such a criterion cannot be employed in endeavoring to separate cryptic and mimietic phenomena in a consistent fashion'. We believe that comparing and contrasting different quantitative methods can give objective information that can separate these 2 aspects of resemblance. Our study and others (Bauer 1981, Robinson 1981, Endler 1984), point to the means and importance of distinguishing between general resemblance (camouflage) and 
specific resemblance (plant-part mimicry) for these 2 methods of resemblance can have very different ecological and evolutionary consequences for animals.

\section{Predators found in Sargassum}

To understand how animals use camouflage and mimicry to avoid predation, we must know what the predators are and how they perceive their prey. At least 3 genera of fish feed almost exclusively on amphipods and decapods living in pelagic Sargassum (see Dooley 1972, Smith 1973 for stomach contents data). These are the Sargassum fish Histrio histrio, various filefishes Stephanolepis spp., and the pipefish Syngnathus pelagica. We only found Histrio in our samples (Table 1). It belongs to the family Antennariidae, renowned for their aggressive camouflage and ambush predation behavior (Dooley 1972, Pietsch \& Grobecker 1990). These amazing fish have an extension of the dorsal fin that serves as a lure, and disruptive coloring that makes them very hard to find in their natural surroundings (Pietsch \& Grobecker 1990). These characteristics together with their large mouth cavity (12 times larger open than closed; Grobecker \& Pietsch 1979), the fastest oral expansion capabilities known for any fish (less than $6 \mathrm{~ms}$ for some species; Grobecker \& Pietsch 1979), and a sit-and-wait predation strategy make these fish formidable predators for even the fastest prey. Given this type of predation pressure, one might expect highly evolved camouflage and mimicry in Sargassum shrimps to reduce the probability of being detected, since once seen they would have little chance of escape from such a fast-reacting predator in the tangle of Sargassum fronds.

Although this study did not consider directly the effect of predation on the resulting densities of shrimps in different habitat architectures and colors, it did show that the presence of an enclosed predator does not change their choice of habitat. Leber (1985) found similar results with Latreutes in a seagrass habitat. The structural complexity of the seagrass habitat alone largely explained the variation in density of Latreutes even when a predator was allowed to forage among the plants. Although predation depressed Latreutes abundances relative to predation exclusion cages, the depression was constant across varying habitat architectures. This suggests that the choice of habitat by these shrimp is not proximally caused by predation pressure; however, it may be the ultimate cause. Exactly what mechanisms(s) protect these shrimps from detection by predators is still not known but it seems likely that general and specific resemblance disrupt the search image (Tinbergen 1960) and/or increase the search rate (Guilford \& Dawkins 1987) of the fish predators.
In this study we emphasize the importance of habitat architecture and color in describing the process of camouflage and plant-part mimicry. An analysis of the size, color and behavioral responses of the camouflaged or mimic animals can be very useful in discovering whether these shrimps resemble their Sargassum habitat sufficiently to avoid detection by predators. Since the proximate cause of habitat choice in this study, and others (Hacker \& Steneck 1990), can be correlated with the architecture and color of the habitat alone, and the use of such methods has largely been overlooked in studies of camouflage and mimicry, we believe that this type of analysis is a useful approach to experimental research involving prey and their predators.

Acknowledgements. We thank C. Diebel, R. Findlay, M. Hay, R. Steneck, R. Wahle and an anonymous reviewer for their helpful comments regarding this manuscript. Special thanks to P. Kremer for use of a 'well-seasoned' dip-net. This work was supported by the NSF under grant number OCE-8818503 to L.P.M. and the Biology Department at W.H.O.I. This is contribution no. 7530 of the Woods Hole Oceanographic Institution.

\section{LITERATURE CITED}

Adams, J. A. (1960). A contribution to the biology and postlarval development of the Sargassum fish, Histrio histrio (Linnaeus), with a discussion of the Sargassum complex. Bull. mar. Sci. Gulf Caribb. 10: 55-82

Barry, C. K. (1974). Role of form vision in habitat selection of the grass shrimp Hippolyte californiensis. Mar. Biol. 26: $261-270$

Bauer, R. T. (1981). Color patterns of the shrimps Heptacarpus pictus and $H$. paludicola (Caridea: Hippolytidae). Mar. Biol. 64: 141-152

Bedford, G. O. (1978). Biology and ecology of the Phasmatodea. Ann. Rev. Entomol. 23: 125-149

Bowman, T E., Wasmer, R. A. (1984). The deep-sea amphipod Paracyphocaris praedator (Gammaridea: Lysianassidae) associated with the pelagic shrimp Oplophorus novaezeelandiae as an egg-mimic. Proc. Biol. Soc. Wash. 97: $844-848$

Brown, F. A. Jr (1939). The coloration and color changes of the gulf-weed shrimp, Latreutes fucorum. Am. Nat. 73: $564-568$

Carlberg, U. (1986). Phasmida biological review. Zool. Anz. 216: $1-18$

Cloudsley-Thompson, J. L. (1981). Comments on the nature of deception. Biol. J. Linn. Soc. 16: 11-14

Cott, H. B. (1957). Adaptive coloration in animals. Methuen, London

Coull, B. C., Wells, J. B. J. (1983). Refuges from fish predation: experiments with phytal meiofauna from the New Zealand rocky intertidal. Ecology 64: 1599-1609

Czaplicki, J. A., Porter, R. H., Wilcoxon, H. C. (1975). Olfactory mimicry involving garter snakes and artificial models and mimics. Behavior 54: 60-71

Dooley, J. K. (1972). Fishes associated with the pelagic Sargassum complex, with a discussion of the Sargassum community. Contrib. mar. Sci. 16: 1-32 
Eberhard, W. G. (1977). Aggressive chemical mimicry by a bolas spider. Science 198: 1173-1175

Eggleston, D. B., Lipcius, R. N., Miller, D. L., Coba-Cetina, L. (1990). Shelter scaling regulates survival of juvenile Caribbean spiny lobster Panularis argus. Mar. Ecol. Prog. Ser 62: $79-88$

Endler, J. A. (1978). A predator's view of animal color patterns Evol. Biol. 11 319-364

Endler, J. A (1981). An overview of the relationships between mimicry and crypsis. Biol. J. Linn. Soc. 16: 25-31

Endler, J. A. (1984). Progressive background in moths, and a quantitative measure of crypsis. Biol. J. Linn. Soc. 84 $187-231$

Feltmate, B. W., Baker, R. L., Pointing, P. J. (1986). Distribution of the stonefly nymph Paragnetina media (Plecoptera: Perlidae): influence of prey, predators, current speed, and substrate composition. Can. J. Aquat. Sci. 43: 1582-1587

Fenton, M. B., Fullard, J. H. (1981). Moth hearing and the feeding strategies of bats. Am. Sci. 69: 266-275

Grobecker, D. B., Pietsch, T. W. (1979). High-speed cinematographic evidence for ultrafast feeding in antennariid anglerfishes. Science 205: 1161-1162

Guilford, T., Dawkins, M. S. (1987). Search images not proven: a reappraisal of recent evidence. Anim. Behav. 35: 1838-1845

Gurney, R. (1936). Notes on some decapod crustacea of Bermuda. II. The species of Hippolyte and their larvae. Proc Zool. Soc. Lond. 106: 25-32

Hacker, S. D., Steneck, R. S. (1990). Habitat architecture and the abundance and body-size-dependent habitat selection of a phytal amphipod. Ecology 71: 2269-2285

Hay, M. E., Duffy, J. E., Fenical, W. (1990). Host-plant specialization decreases predation on a marine amphipod: an herbivore in plant's clothing. Ecology 71: 733-743

Hay, M. E., Duffy, J. E., Pfister, C. A., Fenical, W. (1987). Chemical defenses against different marine herbivores: are amphipods insect equivalents? Ecology 68: 1567-1580

Heck, K. L. Jr, Wetstone, G. S. (1977). Habitat complexity and invertebrate species richness and abundance in tropical seagrass meadows. J. Biogeogr. 4: 135-142

Holmlund, M. B., Peterson, C. H., Hay, M. E. (1990). Does algal morphology affect amphipod susceptibility to fish predation? J. exp. mar. Biol. Ecol. 139: 65-83

Holomuzki, J. R., Short, T M. (1988). Habitat use and fish avoidance behaviors by the stream-dwelling isopod Lirceus fontinalis. Oikos 52: 79-86

Huffaker, C. B. (1958). Experimental studies on predation: dispersion factors and predator-prey oscillations. Hilgardia 27: $343-383$

Kareiva, P., Sahakian, R. (1990). Tritrophic effects of a simple architectural mutation in pea plants. Nature, Lond. 345: $433-434$

Keith, D. E. (1971). Substrate selection in caprellid amphipods of Southern California, with emphasis on Caprella califor-

This article was presented by M. Hay, Morehead City, N. Carolina, USA nica Stimpson and Caprella equilibra Say (Amphipoda). Pacif. Sci. 25: 387-394

Kettlewell, H. B. D. (1956). Further selection experiments on industrial melanism in the Lepidoptera. Heredity 10: 287-301

Leber, K. M. (1985). The influence of predatory decapods, refuge, and microhabitat selection on seagrass communities. Ecology 66: 1951-1964

Littler, D. S., Littler, M. M., Bucher, K. E., Norris, J. N. (1989). Marine plants of the Caribbean. Smithsonian Institution Press, Washington, D.C.

Main, K. L. (1987). Predator avoidance in seagrass meadows: prey behavior, microhabitat selection, and cryptic coloration. Ecology 68: 170-180

Nilsson, D.-E., Nilsson, H. L. (1983). Eye camouflage in the isopod crustacean Astacilla longicornis (Sowerby). J. exp. mar. Biol. Ecol. 68: 105-110

Patton, W. K., Patton, R. J., Barnes, A. (1985). On the biology of Gnathophylloides mineri, a shrimp inhabiting the sea urchin Tripneustes ventricosus. J. Crust. Biol. 5: 616-626

Pietsch, T. W., Grobecker, D. B. (1990). Frogfishes. Scient. Am. 262: 96-103

Robinson, M. H. (1969). Defenses against visually hunting predators. In: Dobzhansky, T., Hecht, M. K., Steere, W. C. (eds.) Evolutionary biology, Vol. 3. Meredith, New York, p. 225-259

Robinson, M. H. (1970). Animals that mimic parts of plants. Morris A.rbor. Bull. 21: 51-58

Robinson, M. H. (1981). A stick is a stick and not worth eating: on the definition of mimicry. Biol. J. Linn. Soc. 16: 15-20

Sisson, R. F. (1976). Adrift on a raft of Sargassum. Natl. Geogr. 149: $116-122$

Smith, K. L. Jr. (1973). Energy transformations by the Sargassum fish, Histrio histrio (L.). J. exp. mar. Biol. Ecol. 12: 219-227

Tinbergen, L. (1960). The natural control of insects in pine woods. I. Factors influencing the intensity of predation by songbirds. Arch. neerl. Zool. 13: 265-343

Vane-Wright, R. I. (1980). On the definition of mimicry. Biol. J. Linn. Soc. 13: 1-6

Wellborn, G. A., Robinson, J. V. (1987). Microhabitat selection as an antipredator strategy in the aquatic insect Pachydiplax longipennis Burmeister (Odonata: Libellulidae). Oecologia 71: 185-189

Wickler, W. (1968). Mimicry in plants and animals. McGrawHill Book Co., New York

Wicksten, M. K. (1980). Decorator crabs. Scient. Am. 242: 116-122

Wicksten, M. K. (1983). Camouflage in marine invertebrates. Oceanogr. mar. Biol. A. Rev. 21: 177-193

Williams, A. B. (1984). Shrimps, lobsters, and crabs of the Atlantic coast of the Eastern United States, Maine to Florida. Smithsonian Institution Press, Washington, D.C.

Manuscript first received: October 4, 1990

Revised version accepted: December 12, 1990 